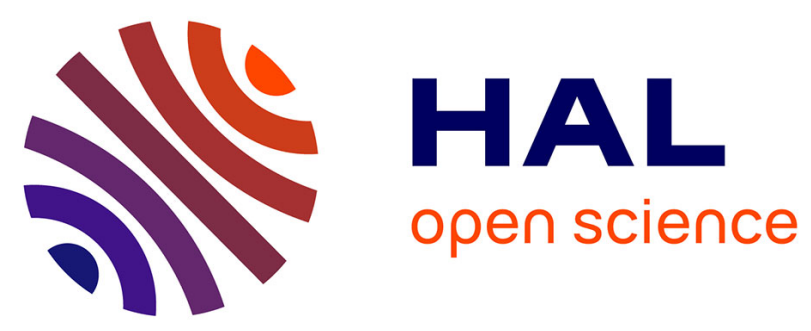

\title{
Prevalence and Impact of Malnutrition in Patients Surgically Treated for Chronic Mesenteric Ischemia
}

Charlotte Allain, Guillaume Besch, Nicolas Guelle, Simon Rinckenbach, Lucie Salomon Du Mont

\section{- To cite this version:}

Charlotte Allain, Guillaume Besch, Nicolas Guelle, Simon Rinckenbach, Lucie Salomon Du Mont. Prevalence and Impact of Malnutrition in Patients Surgically Treated for Chronic Mesenteric Ischemia. Annals of Vascular Surgery, 2019, 58, pp.24 - 31. 10.1016/j.avsg.2019.02.009 . hal-03486158

\author{
HAL Id: hal-03486158 \\ https://hal.science/hal-03486158
}

Submitted on 20 Dec 2021

HAL is a multi-disciplinary open access archive for the deposit and dissemination of scientific research documents, whether they are published or not. The documents may come from teaching and research institutions in France or abroad, or from public or private research centers.
L'archive ouverte pluridisciplinaire HAL, est destinée au dépôt et à la diffusion de documents scientifiques de niveau recherche, publiés ou non, émanant des établissements d'enseignement et de recherche français ou étrangers, des laboratoires publics ou privés.

\section{(ㄷ)(1) $\$$}

Distributed under a Creative Commons Attribution - NonCommerciall 4.0 International 
8 Charlotte ALLAIN, ${ }^{1}$ Guillaume BESCH, ${ }^{2,3}$ Nicolas GUELLE, ${ }^{4}$ Simon RINCKENBACH, ${ }^{1,2}$ Lucie

9 SALOMON DU MONT ${ }^{1,2}$

${ }^{1}$ Department of vascular surgery, Besançon University Hospital, Besançon, France

${ }^{2}$ EA3920, Besançon University Hospital, Besançon, France

${ }^{3}$ Department of anesthesiology, Besançon University Hospital, Besançon France

${ }^{4}$ Vascular surgery unit, Clinique Saint-Vincent, Besançon, France

Correspondance : Lucie Salomon du Mont, Service de chirurgie vasculaire, CHRU de 


\section{ABSTRACT}

Objectives: The patients suffering from chronic mesenteric ischemia are at risk of malnutrition due to the fear of food and the weight loss. However the impact of malnutrition on the morbi-mortality at the time of surgery remains little studied, just as its prevalence. The main objective of this study was to evaluate the influence of malnutrition on the survival of the patients operated for chronic mesenteric ischemia. The secondary objectives were to evaluate the prevalence of malnutrition in this population and to evaluate the early complications after surgery according to the nutritional condition of the patients.

Material and methods: We conducted a monocentric retrospective observational study including consecutively all the patients operated for chronic mesenteric ischemia between 2005 and 2016. The nutritional status was determined a posteriori according to the criteria of the French High Health Authority using the body mass index, the percentage of weight loss and albumin. We thus divided the patients into two groups, "malnourished" and "nonmalnourished". We compared the survival of the patients of the two groups with a log rank test.

Results: We enrolled 54 patients including 35 men (65\%), with a mean age of 68.1 years ( \pm 12.3). The prevalence of malnutrition was $70 \%$ (38 patients), including nine severely malnourished patients (23.6\%). Twenty-nine patients (53.7\%) were treated by endovascular technique and twenty-five had conventional surgery (46.3\%). The type of management was not different between the two groups: 20 patients of the malnourished group (52.6\%) and nine patients of the non-malnourished group (56.3\%) were treated by endovascular technique $(p=0.8)$. The 30 -day mortality was null in the non-malnourished group whereas ten patients $(26.3 \%)$ died in the malnourished group $(p=0.02)$. The short-term complications were not significantly different between the malnourished and the non-malnourished groups ( $37 \%$ vs. $19 \%, p=0.32$ ). The mean duration of follow-up was 639 days $( \pm 660)$.The $3-$ year survival was not different between the endovascular group and the open surgery group ( $43 \%$ vs. $52 \%, p=0.7$ ). The 3 -year survival was statistically higher in the non-malnourished group (87\%) than in the malnourished group (49.6\%) $(p=0.01)$.

Conclusion: In our experience, preoperative malnutrition is a factor significantly decreasing the survival of the patients treated with open surgery or with endovascular technique for 
chronic mesenteric ischemia. A more optimal preoperative management of this malnutrition could improve the results of these procedures.

\section{INTRODUCTION}

The weight loss observed with chronic intestinal ischemia is related to a fear of food due the postprandial pain linked with the ingestion of aliments ${ }^{1}$ and to the digestive disorders generated by the chronic functional ischemia of the intestine. ${ }^{1,2}$ This causes a more or less severe malnutrition according to the duration of the symptoms.

It is now well recognized that malnutrition lower the prognosis in the event of a surgical management. ${ }^{3}$ It was initially studied in digestive surgery, and $\mathrm{Hu}$ et al. ${ }^{4}$ observed that albumin rates lower than $3.5 \mathrm{~g} / \mathrm{dL}$ were a predictive factor of postoperative complications after surgery for colorectal cancer; in addition, in oncologic thoracic surgery, Bangan et al.5 showed that malnutrition was a predictive factor of postoperative infectious complications and of mortality after pneumonectomy. In the DENUCRITICC study, malnutrition was the only risk factor associated with the 30-day mortality after vascular surgery for chronic critical ischemia of the lower limbs. ${ }^{6}$ However, no study until now evaluated the role of malnutrition as a risk factor after mesenteric conventional or endovascular revascularization for chronic mesenteric ischemia. Similarly the prevalence of malnutrition was not really evaluated according to the current accepted definitions. ${ }^{7}$ Whereas some authors evoked the concept of weight loss, present in $93 \%$ of the patients of Kihara et al. ${ }^{8}$ and $84 \%$ of the patients of Cho at al. ${ }^{9}$ treated for chronic intestinal ischemia, none of them based on the current criteria of malnutrition.

The main objective of this study was to evaluate the influence of malnutrition on the survival of the patients operated for chronic mesenteric ischemia. The secondary objectives were to evaluate the prevalence of malnutrition in this population of patients and the early postoperative complications according to the nutritional state of the patients.

\section{METHODS}

We retrospectively enrolled all the patients treated by conventional surgery or endovascular techniques for chronic mesenteric ischemia with revascularization of the digestive arteries in the Besançon University Hospital between January 2005 and December 2016. Patients were diagnosed with chronic mesenteric ischemia in presence of clinical and radiological signs. 
The clinical signs included post prandial chronic abdominal pain, diarrheas, constipation and/or weight loss. Imaging techniques were Doppler ultrasound and/or CT-scan which showed one or more lesions of the digestive arteries. The lesions were considered as significant in the presence of $a>50 \%$ stenosis. The patients treated for an acute mesenteric ischemia or for a syndrome of the arcuate ligament and those who did not have revascularization because of extensive intestinal necrosis discovered during operation were excluded from the analysis.

We recorded the demographic data (age and gender) and the cardiovascular risk factors (active or discontinued smoking, insulin dependent or not diabetes mellitus, arterial hypertension (HBP), dyslipidemia), coronary artery disease (previous myocardial revascularization with stent or bypass), impaired renal function (clearance $<60 \mathrm{~mL} / \mathrm{min}$ according to the method of Cockroft and Gault), the need for dialysis or not, heart failure, chronic obstructive bronchopneumopathy (COBP) scored higher than 1 according to the Gold classification, ${ }^{10}$ and the presence of peripheral arterial disease (PAD) treated by surgery or not. We collected the symptoms of mesenteric ischemia: abdominal pain, postprandial pain and weight loss, and we recorded the use of perioperative parenteral nutrition. We also collected the type of bypass carried out (anterograde or retrograde) for open surgery, and the number of revascularized arteries as well as the use of stents in case of endovascular treatment. The type of surgical management was chosen according to the comorbidities of the patient, the type of lesion, and the number of involved arteries. Multiple mesenteric occlusive disease or lesions associated with aortic atheroma or an aortic aneurysm were preferentially treated by open surgery. Stenoses were treated by endovascular technique. The surgical success was defined by the patency of the revascularized artery on the postoperative imagery. All the patients were reviewed three months after the operation with the results of digestive arteries Doppler or an angio-CT if this examination was considered more appropriate given the echogenicity of the patient.

We used the criteria of the French High Health Authority $(\mathrm{HAS})^{7}$ to determine the nutritional status of the patients including the kinetics of weight loss, the body mass index, and albumin and pre-albumin levels (Table I). The diagnosis of malnutrition was retained if the patient presented at least one of these four criteria: body mass index (BMI) $<18.5 \mathrm{~kg} / \mathrm{m}^{2}$ or $\mathrm{BMI}<21 \mathrm{~kg} / \mathrm{m}^{2}$ in patients older than 70 years, recent loss in weight $>10 \%$, albumin $<35$ 
$\mathrm{g} / \mathrm{L}$ or pre-albumin $<0.25 \mathrm{~g} / \mathrm{L}$. If the BMI was $<18 \mathrm{~kg} / \mathrm{m}^{2}$ or $<16 \mathrm{~kg} / \mathrm{m}^{2}$ in patients $<70$ years, if the weight loss was $>10 \%$ in one month or if the albumin level was $<30 \mathrm{~g} / \mathrm{L}$ or the prealbumin level was $<0.15 \mathrm{~g} / \mathrm{L}$, the patient was regarded as severely malnourished. The patients were thus classified in two groups: malnourished and non-malnourished.

The primary endpoint was long term survival. Secondary endpoints were early postoperative complications within 30 days. Organ failure (acute renal failure, cardiogenic or infectious acute respiratory distress), infectious and hemorrhagic complications, mild or acute recurrent mesenteric ischemia due to restenosis, thrombosis or dissection of the treated arteries and early deaths (i.e. within the month following surgery) were regarded as postoperative complications. To evaluate these criteria, we used the data of the medical files and the reports of the follow-up visits by the surgeons and the angiologists.

\section{Statistical analysis}

The statistical analysis was carried out with the SAS software (version 9.4; SAS Institute, Cary, NC, USA). The data are presented as mean (standard deviation) and number (percentage). The Fisher exact and the $\mathrm{Chi}^{2}$ tests were applied to compare qualitative variables. The Student's t test was used for quantitative variables. The survival analysis was carried out using the Kaplan Meier method with a log-rank test. $p<0.05$ was considered statistically significant.

\section{RESULTS}

During the study period, 55 patients were hospitalized for chronic mesenteric ischemia. One patient could not be revascularized due to extensive intestinal necrosis. Fifty-four patients were thus included, 35 men and 19 women. The mean age of the population was $68.1 \pm$ 12.3 years. The average BMI was $21.3 \pm 4.5 \mathrm{~kg} / \mathrm{m}^{2}$. We collected the preoperative symptoms presented by the patients. Only one patient did not present spontaneous abdominal pain. Thirty-four patients (63\%) presented postprandial pain and $40(74.1 \%)$ presented weight loss.

Twenty-nine patients (54\%) were treated by endovascular techniques while 25 (46\%) had an open revascularization. Concerning open surgery, complete revascularization was carried out in 11 patients (44\%), and when all the blocked arteries were not treated, the revascularization of the superior mesenteric artery was favored. Moreover, when a bypass 
was carried out, anterograde revascularization was favored (six out of eight bypassed patients (75\%) undergoing bypass). In addition, five endarterectomies and 13 reimplantations of digestive arteries were carried out in $19 \%$ and $50 \%$ of the patients treated by conventional surgery, respectively. Nine patients treated by open surgery had concomitant aortic surgery, six for aneurysm and three for occlusive disease.

Concerning the endovascular approach, we treated one arterial axis, mainly the superior mesenteric artery. Thus, the superior mesenteric artery was revascularized in twenty-four (83\%) patients revascularized by endovascular technique. In 20 (69\%) patients treated with an e endovascular approach, only this axis was treated. Moreover, $69 \%$ of the patients treated by endovascular technique had stents. Access was femoral in 18 cases (62\%) and brachial in 11 cases (38\%). There was no retrograde endovascular revascularization. One patient had a combined treatment associating the dilation of the celiac trunk with a reimplantation of the superior mesenteric artery.

The prevalence of malnutrition in our population was 70\% (38 patients), including nine (23.6\%) patients severely malnourished. The main criterion we used to define the nutritional status was the body mass index which was missing in one patient. Albumin and pre-albumin rates were obtained in 24 patients and the weight loss was quantified as a function of time in 42 patients. The two populations of malnourished and non-malnourished patients were demographically comparable, and the cardiovascular risk factors (diabetes, BMI, dyslipidemia, HBP, coronary disease, tobacco addiction) and comorbidities (PAD, COPD, impaired renal function, cardiac failure, and respiratory insufficiency) were similar (Table II). The patients who presented postprandial pain were mainly malnourished patients (Table IV). Twenty-eight (73.7\%) of the malnourished patients were symptomatic in post-prandial vs. only six patients $(37.5 \%)$ in the non-malnourished group of patients $(p=0.01)$. The number of diseased arteries was $\geq 2$ in $87.5 \%$ of the cases in the non-malnourished group and $86.8 \%$ in the malnourished group $(p=0.88)$, respectively. At least two arteries were revascularized in $25 \%$ of the cases in the non-malnourished group and $31.6 \%$ of the patients in the malnourished group, and only one artery was treated in $75 \%$ and $68.4 \%$ of the patients in the non-malnourished and malnourished groups, respectively $(p=0,62)$. Twenty patients $(52.6 \%)$ in the malnourished group were treated by endovascular technique vs. nine patients $(56.3 \%)$ in the non-malnourished group $(p=0.8)$. Three patients had preoperative parenteral 
nutrition (5.5\%). Two of them were malnourished. The nutrition protocol lasted five days. It can be noted that the three patients receiving parenteral nutrition did not present postoperative complications or early death.

At 30 days, the early complications were not significantly different between the malnourished and non-malnourished groups (36.8\% vs. $18.7 \% p=0.32)$. Sixteen patients presented complications within thirty days following the surgery: three acute renal failures, four acute respiratory insufficiencies with two deaths, one hemorrhagic shock leading to death, three multiple organ failures leading to death, one aortic perished hematoma which required surgery, one thrombosis of an aorto-bifemoral prosthesis, one stenosis of a superior mesenteric artery stent and two cases of acute mesenteric ischemia leading to the death of the patient. In the same way, there no was difference in the surgical success rates $(87 \%$ vs. $94 \% p=0.65)$ and in the rates in reintervention $(15.7 \%$ vs. $18.7 \% p=1)$ between the malnourished and the non-malnourished groups. However, there was no 30-day death in the patients of the non-malnourished group whereas nine $(23.6 \%)$ of the patients died in the malnourished group $(p=0.04)$. Six procedures did not allow a satisfactory revascularization, with a persistent symptomatology postoperatively and aggravation, with one case of immediate postoperative acute mesenteric ischemia. Five of these patients were malnourished. Five failures of revascularization were observed after angioplasty of the superior mesenteric artery without stent. All these patients had reintervention by open surgery, and two of them died early from multiple organ failure.

The average follow-up was $639 \pm 660$ days. The 3 -year survival was higher in the nonmalnourished group (87\%) than in the malnourished group (49.6\%) ( $p=0.03$ ) (Fig. 1).

\section{DISCUSSION}

Our study made it possible to highlight a strong proportion of malnourished patients (71\%), according to the current criteria of the HAS, in a population treated surgically for chronic mesenteric ischemia. The impact of malnutrition on mortality was significant at 30 days since the only early deaths occurred in the malnourished group with a $23.6 \% 30$-day mortality rate vs. the absence of mortality in the non-malnourished group, $(p=0,04)$. This impact continued in the long run with a 3 -year survival rate of $49.6 \%$ in the malnourished group vs. $87 \%$ in the non-malnourished group $(p=0.01)$. 
In the current literature the problems linked with malnutrition in this pathology remain little studied. The percentage of patients presenting weight loss varies according to the studies, but the majority of the patients are always concerned, as in our population. David et al. reported a weight loss in $73.5 \%$ of the patients presenting with chronic mesenteric ischemia. ${ }^{11}$ In the monocentric retrospective study of Maximillien et al., $53.1 \%$ of the patients only presented a weight loss. ${ }^{12}$ Tallarita at al. found a prevalence of weight loss of 83\%. ${ }^{13}$ Brown et al. recommended endovascular revascularization as the first line of treatment in patients presenting a high surgical risk or a significant malnutrition in view of the lower perioperative risk of this technique. ${ }^{11}$ That suggests a higher surgical risk in malnourished patients.

The study by Tallarita et al., published in 2015, included 343 patients between 1991 and 2010 and reported the survival of the patients having surgery for chronic mesenteric ischemia. ${ }^{13}$ The results showed 5 -year survival rates of $60 \%$ and $57 \%$ after open surgery and endovascular treatment, respectively. We observed comparable results. The authors focused on predictive factors of mortality, such as age, chronic renal failure, diabetes or respiratory insufficiency, but malnutrition was not mentioned. The evolution of the practices tends however towards the use of endovascular technique with the emergence of more and more adapted tools to revascularize the digestive arteries.

Several publications reported a lower immediate morbi-mortality with endovascular treatment compared with open surgery. ${ }^{14}$ As such, a retrospective study conducted from the "National Inpatient Sample" database included 15.475 patients treated for chronic mesenteric ischemia between 2000 and 2014. Seventy percent of the patients had been treated by endovascular route and $29.4 \%$ by open surgery. ${ }^{15}$ In-hospital mortality after endovascular treatment was $2.4 \%$ vs. $8.7 \%$ for open surgery. However the long term results appear better with open surgery. ${ }^{16}$ In our experience the proportions of patients treated by endovascular and open surgery were similar in the two groups, with $52.6 \%$ and $56.3 \%$ of the patients treated by endovascular route in the malnourished the non-malnourished groups, respectively $(p=0.8)$. In our study we did not observe any significant influence of the type of treatment on survival. Indeed, the 30-day survival rates were $96 \%$ and $82.4 \%$ for conventional surgery and endovascular treatment, respectively. Regarding the 3-year 
survival, it was $65.5 \%$ for open surgery and $57.3 \%$ for endovascular treatment $(p=0.7)$. This leads us to consider that the type of treatment did not have any influence on the results.

The early postoperative mortality was $23.6 \%$ in the malnourished patients whereas it was null in non-malnourished patients. This leads to believe that malnutrition is a major risk factor of postoperative mortality in these patients. One approach of improvement would be to promote nutritional care. The 2017 ESPEN guidelines ${ }^{17}$ recommend perioperative nutritional care in malnourished patients or patients at risk of malnutrition. The ideal is to use protocols to provide a better framework for perioperative re-nutrition, which is generally conducted between 5 and 7 days before and after the surgery. According to these recommendations, the enteral route should be privileged but, in patients suffering from chronic mesenteric ischemia, it is preferable to use the parenteral route due to the high risk of evolution towards an acute mesenteric ischemia. Lastly, these recommendations, just like the last Guidelines of the European Society of Vascular Surgery, specify that perioperative nutrition should never delay surgery, which could become urgent in presence of a chronic mesenteric ischemia. ${ }^{2}$ The SFNCM (French-speaking Society of Clinical Nutrition and Metabolism) proposed to classify the patients according to nutritional grades. These grades, from 1 to 4 , make it possible to stratify the nutritional risk and to propose a management adapted to each group of patients. This classification takes into account the nutritional status of the patient and the type of surgery provided. ${ }^{18}$ Endovascular surgery is thus considered as a low risk surgery while open surgery is classified as high-risk surgery. In malnourished patients, a seven to ten days preoperative parenteral nutrition is already proposed before cardiac and carcinological digestive surgery with a $10 \%$ reduction in postoperative complications. ${ }^{19}$ But those measures of re-nutrition will be ineffective if they are postoperative only. Indeed, nine prospective randomized studies including 726 patients showed that postoperative parenteral nutrition increased postoperative complications by $10 \%$ without any significant result on mortality. ${ }^{20}$ Recommendations on perioperative nutritional care of patients having a scheduled surgery were published in Annales Françaises d'Anesthésie et de Réanimation in 1994 and updated in 2010. However the last European recommendations for the management of mesenteric ischemia do not recommend preoperative re-nutrition. ${ }^{21}$ The effectiveness of preoperative re-nutrition in patients operated for chronic mesenteric ischemia remains to be shown. In addition, the patients 
with chronic mesenteric ischemia are exposed to the risk of refeeding syndrome. This phenomenon can have as consequences hypophosphatemia, hypokalemia and hypomagnesemia. The clinical manifestations of these deficiencies can lead to multiple organ failure and death. ${ }^{22}$ It is thus necessary to closely monitor the patients under renutrition and to evoke this diagnosis when using re-nutrition in a patient presenting with chronic mesenteric ischemia.

This work presents several limitations. First of all the retrospective collection of data did not allow a homogeneous tracking of malnutrition. Albumin and pre-albumin levels were not always obtained. In the same way, measurements of weight loss were not exhaustive. However, to qualify a patient as malnourished, one of the HAS criteria had to be fulfilled. Thus, patients could be classified in the non-malnourished group due to the lack of data. That tended to make us underestimate the prevalence of the malnourished population in the patients who were operated for chronic mesenteric ischemia. Moreover, the follow-up of the patients was not standardized and some were re-examined during a surgical consultation while others were followed only by their general practitioner. Our study was conducted in our center only with a low power and it would be necessary to set up a largerscale study in several centers to be able to generalize these results to all the patients presenting with chronic mesenteric ischemia. There was no systematic perioperative protocol of re-nutrition in our patients treated with surgery for chronic mesenteric ischemia between 2005 and 2016. Only three patients received a perioperative parenteral renutrition. That could however affect our results. In addition, endovascular techniques evolved considerably between 2005 and 2016. This certainly influenced the type of treatment proposed to our patients and the surgical results but due to the lack of data concerning the type of stent or of balloon used, we cannot measure the impact of these novel methods with precision. The surgical success also did not reach $100 \%$. There were six failures at the time of the first intervention in five patients of the malnourished group. One patient could not be re-operated and died of multiple organ failure. We had to carry out five reinterventions in five patients who still presented symptoms after a first procedure and in which the postoperative imagery showed a significant persistent stenosis in the same location. That could affect our results and increase the postoperative morbi-mortality in the patients of the malnourished group. 


\section{CONCLUSION}

Our study shows that the prevalence of malnutrition in our population of patients presenting chronic mesenteric ischemia was $70 \%$. Malnutrition appeared to be a major risk factor of early postoperative mortality but it also influenced the long term survival in our population of patients. If these results are shown generalizable we could propose a perioperative renutrition for the patients treated for chronic mesenteric ischemia without delaying the intervention.

\section{LEGEND OF FIGURE}

Fig. 1. 3-year survival curves of the malnourished and non-malnourished patients.

\section{REFERENCES}

1. Al-Diery H, Phillips A, Evennett N, Pandanaboyana S, Gilham M, Windsor JA. The Pathogenesis of Nonocclusive Mesenteric Ischemia: Implications for Research and Clinical Practice: Review Article. J Intensive Care Med 2018;885066618788827.

2. M. Björck, M. Koelemay, S. Acosta, F. Bastos Goncalves, T. Kölbel, J.J. Kolkman. Editor's Choice e Management of the Diseases of Mesenteric Arteries and Veins. Clinical Practice Guidelines of the European Society of Vascular Surgery (ESVS). Eur J Vasc Endovasc Surg 2017;53:460-510.

3. Van Stijn MFM, Korkic-Halilovic I, Bakker MSM, van der Ploeg T, van Leeuwen PAM, Houdijk APJ. Preoperative nutrition status and postoperative outcome in elderly general surgery patients: a systematic review. JPEN 2013;37:37?43.

4. Hu W-H, Cajas-Monson LC, Eisenstein S, Parry L, Cosman B, Ramamoorthy S. Preoperative malnutrition assessments as predictors of postoperative mortality and morbidity in colorectal cancer: an analysis of ACS-NSQIP. Nutr J 2015;14:91.

5. Bagan P, Berna P, De Dominicis F, et al. Nutritional status and postoperative outcome after pneumonectomy for lung cancer. Ann Thorac Surg. 2013;95:392 6.

6. Salomon du Mont L, Leclerc B, Morgant M-C, et al. Impact of Nutritional State on Critical Limb Ischemia Early Outcomes (DENUCRITICC Study). Ann Vasc Surg 2017;45:10?5. 
7. Raynaud-Simon A, Revel-Delhom C, Hébuterne X, French Nutrition and Health Program, French Health High Authority. Clinical practice guidelines from the French Health High Authority: nutritional support strategy in protein-energy malnutrition in the elderly. Clin Nutr 2011;30:312国9.

8. Kihara TK, Blebea J, Anderson KM, Friedman D, Atnip RG. Risk factors and outcomes following revascularization for chronic mesenteric ischemia. Ann Vasc Surg 1999;13:37团44.

9. Cho J-S, Carr JA, Jacobsen G, Shepard AD, Nypaver TJ, Reddy DJ. Long-term outcome after mesenteric artery reconstruction: a 37-year experience. J Vasc Surg 2002;35:453目60.

10. Casanova C, Marin JM, Martinez-Gonzalez C, et al. New GOLD classification: longitudinal data on group assignment. Respir Res 2014;15:3.

11. Brown DJ, Schermerhorn ML, Powell RJ, et al. Mesenteric stenting for chronic mesenteric ischemia. J Vasc Surg 2005;42:268?74.

12. Barret M, Martineau C, Rahmi G, et al. Chronic Mesenteric Ischemia: A Rare Cause of Chronic Abdominal Pain. Am J Med 2015;128:1363.e1-8.

13. Tallarita T, Oderich GS, Gloviczki $P$, et al. Patient survival after open and endovascular mesenteric revascularization for chronic mesenteric ischemia. J Vasc Surg 2013;57:7470155; discussion 754-755.

14. Gupta PK, Horan SM, Turaga KK, Miller WJ, Pipinos II. Chronic mesenteric ischemia: endovascular versus open revascularization. J Endovasc Ther 2010;17:540?9.

15. Erben $Y$, Jean RA, Protack CD, Chiu AS, Liu S, Sumpio BJ, et al. Improved mortality in treatment of patients with endovascular interventions for chronic mesenteric ischemia. J Vasc Surg 2018;67:1805?12.

16. Lejay A, Georg Y, Tartaglia E, et al. Chronic mesenteric ischemia: 20 year experience of open surgical treatment. Eur J Vasc Endovasc Surg 2015;49:587?92.

17. Weimann A, Braga M, Carli F, et al. ESPEN guideline: Clinical nutrition in surgery. Clin Nutr 2017;36:623-50

18. Chambrier C, Sztark F, groupe de travail de la Société francophone de nutrition clinique et métabolisme (SFNEP) et de la Société française d'anesthésie et réanimation (SFAR). 
French clinical guidelines on perioperative nutrition. Update of the 1994 consensus conference on "Perioperative artificial nutrition after elective surgery in adults ". Ann Fr Anesth Reanim 2011;30:381目9.

19. Zazzo J-F. Preoperative screening and nutritional support of nutritional deficiencies. Ann



20. Klein S, Kinney J, Jeejeebhoy K, et al. Nutrition support in clinical practice: review of published data and recommendations for future research directions. National Institutes of Health, American Society for Parenteral and Enteral Nutrition, and American Society for Clinical Nutrition. JPEN 1997;21:133056.

21. Pecoraro F, Rancic Z, Lachat $M$, et al. Chronic mesenteric ischemia: critical review and guidelines for management. Ann Vasc Surg 2013;27:113?22.

22. Preiser J-C, van Zanten ARH, Berger MM, et al. Metabolic and nutritional support of critically ill patients: consensus and controversies. Crit Care. 2015;19:35. 


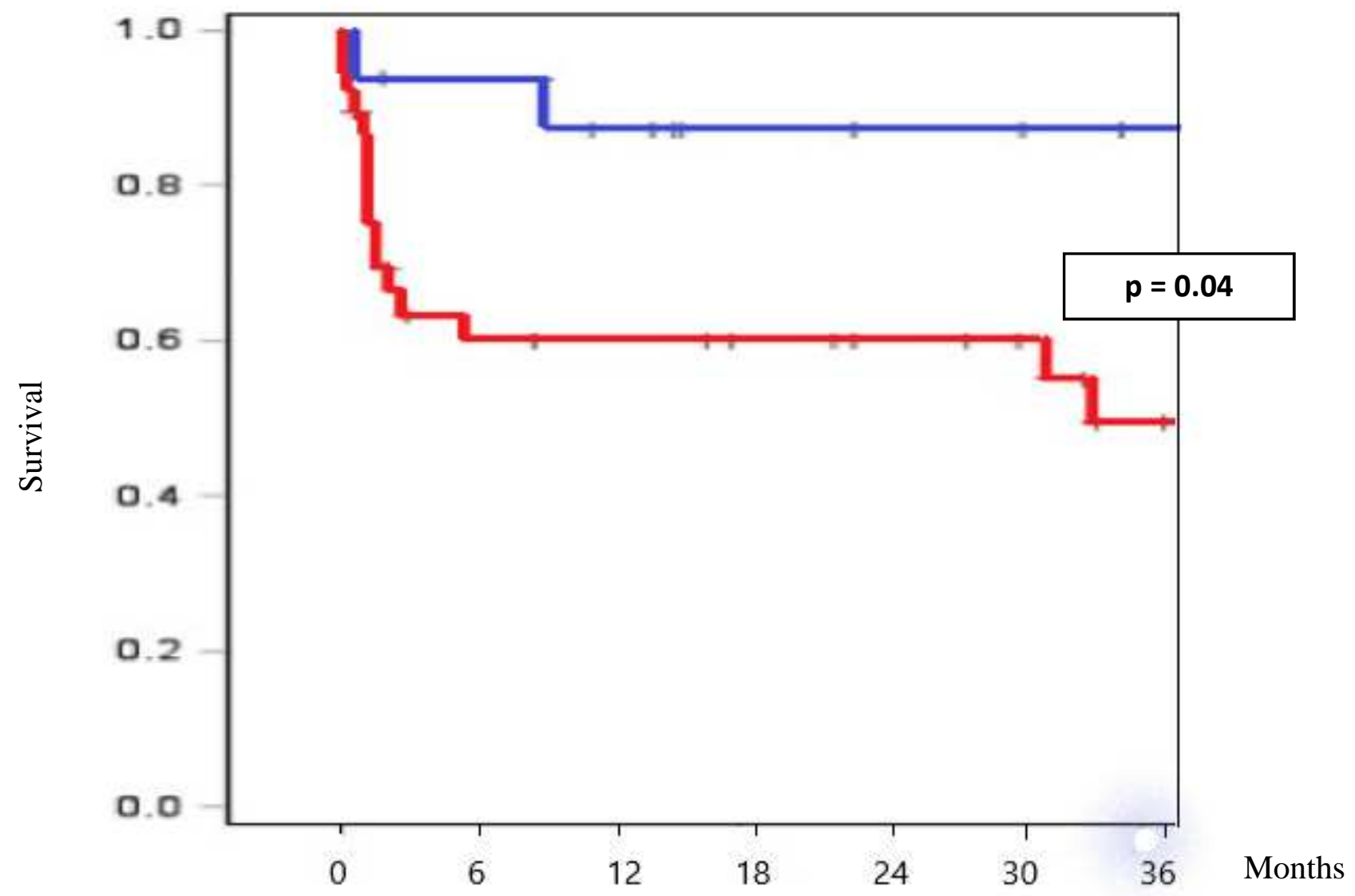

Number at risk

$\begin{array}{lccccccc}\text { malnourished } & 38 & 19 & 18 & 16 & 14 & 11 & 6 \\ \begin{array}{l}\text { non-malnourished } \\ \text { patients }\end{array} & 16 & 14 & 12 & 9 & 8 & 7 & 5\end{array}$

[Tapez ici] 
Table I. 2007 clinical and paraclinical criteria for the diagnosis of malnutrition according the HAS $^{7}$

\begin{tabular}{lll}
\hline & Malnutrition & Severe malnutrition \\
\hline Weight loss & $\begin{array}{l}>5 \% \text { in one month or }>10 \% \text { in } \\
\text { six months }\end{array}$ & $\begin{array}{l}>10 \% \text { in one month or }>15 \% \\
\text { in six months }\end{array}$ \\
Body mass index & $\begin{array}{l}<21 \mathrm{~kg} / \mathrm{m}^{2}\left(18.5 \mathrm{~kg} / \mathrm{m}^{2} \text { over70 }\right. \\
\text { years })\end{array}$ & $\begin{array}{l}<18 \mathrm{~kg} / \mathrm{m}^{2}\left(16 \mathrm{~kg} / \mathrm{m}^{2} \text { in }\right. \\
\text { patients }<70 \text { years })\end{array}$ \\
Albumin & $<35 \mathrm{~g} / \mathrm{L}$ & $<30 \mathrm{~g} / \mathrm{L}$ \\
Pre-albumin & $0.15-0.25 \mathrm{~g} / \mathrm{L}$ & $<0.15 \mathrm{~g} / \mathrm{L}$ \\
\hline
\end{tabular}


Table II. Characteristics of the malnourished and non-malnourished groups

\begin{tabular}{|c|c|c|c|c|}
\hline & $\begin{array}{l}\text { Total population } \\
\qquad \begin{array}{c}N=54 \\
N(\%)\end{array}\end{array}$ & $\begin{array}{c}\text { Malnourished } \\
\text { patients } \\
\mathrm{N}=38(70 \%) \\
\mathrm{N}(\%)\end{array}$ & $\begin{array}{c}\begin{array}{c}\text { Non-malnourished } \\
\text { patients }\end{array} \\
\mathrm{N}=16(30 \%) \\
\mathrm{N}(\%)\end{array}$ & $\bar{p}$ \\
\hline Men & $35(64.8)$ & $25(65.7)$ & $10(62.5)$ & 0.82 \\
\hline Age * & $68.2+/-12.3$ & $67.3+/-13$ & $70.2+/-10.7$ & 0.44 \\
\hline $\mathrm{BMI} * 1$ & $21.4+/-4.5$ & $19.7+/-4$ & $25.3+/-2.9$ & $<10^{-3}$ \\
\hline Diabetes & $14(25.9)$ & $10(26.3)$ & $4(25)$ & 0.92 \\
\hline Dyslipidemia & $37(68.5)$ & $24(63.2)$ & $13(81.2)$ & 0.19 \\
\hline $\mathrm{HBP} * 2$ & $46(85.2)$ & $31(81.6)$ & $15(93.7)$ & 0.32 \\
\hline Tobacco & $35(64.8)$ & $25(65.8)$ & $10(62.5)$ & 0.82 \\
\hline Coronary disease & $24(44.4)$ & $16(42.1)$ & $8(50)$ & 0.59 \\
\hline $\mathrm{COBP} * 3$ & $14(25.9)$ & $11(28.9)$ & $3(18.7)$ & 0.43 \\
\hline Heart failure & $12(22.2)$ & $9(23.7)$ & $3(18.7)$ & 0.69 \\
\hline Respiratory insufficiency & $7(12.9)$ & $7(18.4)$ & $0(0)$ & 0.07 \\
\hline $\mathrm{PAD}^{* 4}$ & $30(55.5)$ & $19(0.50)$ & $11(68.7)$ & 0.20 \\
\hline Renal failure ${ }^{*^{5}}$ & $10(18.5)$ & $7(18.4)$ & $3(18.7)$ & 0.98 \\
\hline Open surgery & $25(46.3)$ & $18(47.4)$ & $7(43.7)$ & 0.81 \\
\hline
\end{tabular}

*results presented as mean (standard deviation), ${ }^{* 1} \mathrm{BMI}$ (body mass index), ${ }^{* 2} \mathrm{HBP}$ (arterial hypertension), ${ }^{* 3}$ COPD (chronic obstructive pulmonary disease higher than stage I of Gold, ${ }^{* 4}$ PAD (peripheral arterial disease) $*^{*}$ clearance $<60 \mathrm{~mL} / \mathrm{min}$ (with dialysis or not). 
Table III. Comparison of the postoperative results in the non-malnourished and malnourished groups

\begin{tabular}{llll}
\hline & Non-malnourished & Malnourished & $\mathrm{P}$ \\
$\mathrm{N}=16$ & $\mathrm{~N}=38$ & \\
$\mathrm{~N}(\%)$ & $\mathrm{N}(\%)$ & 0.03 \\
\hline 30-day death & $0(0)$ & $9(23.6)$ & 0.19 \\
$\begin{array}{l}\text { Postoperative } \\
\text { complications }\end{array}$ & $8(18.7)$ & $14(36.8)$ & 0.92 \\
Re-intervention & $3(18.7)$ & $6(15.7)$ & 0.46 \\
Technical success & $15(94)$ & $33(87)$ & \\
\hline
\end{tabular}

